\title{
3,4-Seco-12 $\alpha$-hydroxy-5 $\beta$-cholan-3,4,24-trioic Acid, a Novel Secondary Bile Acid: Isolation from the Bile of the Common Ringtail Possum (Pseudocheirus peregrinus) and Chemical Synthesis
}

Shoutaro Sekiguchi', Kazunari Namegawa ${ }^{1}$, Naoya Nakane' ${ }^{1}$, Rika Satoh Née Okihara', Kaoru Omura', Lee R Hagey ${ }^{2}$, Alan F Hofmann ${ }^{2}$ and Takashi lida ${ }^{1 *}$

${ }^{1}$ Department of Chemistry, Nihon University, Sakurajosui, Setagaya, Tokyo 156-8550, Japan

${ }^{2}$ Department of Medicine, University of California, San Diego, La Jolla, CA 92093-063, USA

\begin{abstract}
The major bile acids present in gallbladder bile of the common ringtail possum (Pseudocheirus peregrinus), an Australian marsupial, were isolated by preparative HPLC and identified by NMR and by comparison with synthetic standards. The major compound present $(52 \%)$ was $3 \alpha, 12 \alpha$-dihydroxy-7-oxo-5 $\beta$-cholan-24-oic acid (7-oxodeoxycholic acid), about three fourths conjugated with taurine. Also present was $3 \alpha, 7 \beta, 12 \alpha$-trihydroxy-5 $\beta$-cholan24-oic acid (20\%; ursocholic acid) largely in unconjugated form. In addition, 3,4-seco-12a-hydroxy-5 $\beta$-cholan-3,4,24trioic acid was present in unconjugated form and constituted $8 \%$ of biliary bile acids. Proof of the structure of this novel 3,4 -seco acid was obtained by its chemical synthesis from deoxycholic acid via an intermediary $3 \beta, 4 \beta$-dihydroxy derivative that was then oxidatively cleaved with sodium periodate. As all primary bile acids have a hydroxyl or oxo substituent at C-7, the absence of such in the seco-bile acid suggests that it is a secondary bile acid, synthesized by bacterial enzymes present in the intestine.
\end{abstract}

Keywords: Common ringtail possum; Secondary bile acids; $3 \alpha, 7 \beta, 12 \alpha$-Trihydroxy-5 $\beta$-cholan-24-oic acid; $3 \alpha, 12 \alpha$-Dihydroxy-7oxo-5 $\beta$-cholan-24-oic acid; 3,4-Seco-12 $\alpha$-hydroxy-5 $\beta$-cholan-3,4,24trioic acid; Bile acid metabolism

\section{Introduction}

Bile acids $\left(\mathrm{C}_{24}\right.$ and $\left.\mathrm{C}_{27}\right)$ and bile alcohols $\left(\mathrm{C}_{27}\right)$ are the end products of cholesterol metabolism that have multiple physiological functions. After their synthesis bile acids and bile alcohols are made water soluble by "conjugation" with glycine or taurine for bile acids and with sulfate for bile alcohols. In the liver, bile acids stimulate bile flow and solubilize biliary cholesterol. In the small intestine, bile acids solubilize dietary lipids, and in the large intestine, modulate water and electrolyte movement [1,2]. In addition, in the past decade, bile acids have been shown to also possess potent and important signaling properties [3]. Bile acids modulate the expression of multiple genes via the nuclear receptor FXR (farnesoid X receptor) that is activated by bile acids. Bile acids also activate the TGR5 (transmembrane $\mathrm{G}$ proteincoupled receptor 5) and thereby modulate intracellular events. Agents that activate FXR and/or TGR5 are in clinical development for the treatment of cholestatic liver disease and nonalcoholic steatohepatitis.

Bile acid structure varies widely in vertebrates. Haslewood proposed that bile acid structure provides additional phenotypic information for the establishment of phylogenetic relationships [4], and we have extended his pioneering work in a series of papers [5-7].

We report here the biliary bile acid composition of an Australian marsupial, the common ringtail possum (Pseudocheirus peregrinus) (Figure 1), a member of the Pseudocheiridae family of the order Diprotodontia. In particular, we report the presence of a novel 3,4-seco-bile acid whose structure was confirmed by chemical synthesis from deoxycholic acid. We also report that the biliary bile acids of the possum appear to be largely secondary bile acids, formed from primary bile acids by bacterial enzymes. Finally, we relate the biliary bile acid composition of the possum to marsupial phylogeny.

\section{Experimental Procedures}

\section{Biological material}

A bile sample from the common ringtail possum was obtained at necropsy by the Pathology Department of the Zoological Society of San Diego (CA, USA). So far, all attempts to obtain a bile sample from a second possum have failed, but in our experience, biliary bile acid composition is generally quite similar in animals of a given species. The bile was dispersed in 4 volumes of reagent grade 2-propanol and stored at refrigerator temperature until analysis.

\section{Materials and reagents}

The authentic standards that were used to clarify the structures of the natural bile acids are summarized in Figure 2. Evidence for the assignments of each of the structures is presented in the text. Unconjugated $3 \alpha, 7 \beta, 12 \alpha$-trihydroxy-5 $\beta$-cholan-24-oic acid [8] and $3 \alpha, 12 \alpha$-dihydroxy-7-oxo-5 $\beta$-cholan-24-oic acid [9] were conjugated with taurine as described previously [7]. All other chemicals and reagents employed were of analytical reagent grade.

*Corresponding author: Takashi lida, Department of Chemistry, College of Humanities and Sciences, Nihon University, Sakurajosui, Setagaya, Tokyo 156-8550 Japan, Tel: +8133329 1151; E-mail: takaiida@chs.nihon-u.ac.jp

Received November 25, 2016; Accepted December 20, 2016; Published January 02, 2017

Citation: Sekiguchi S, Namegawa K, Nakane N, Okihara RSN, Omura K, et al. (2017) 3,4-Seco-12 $\alpha$-hydroxy-5 $\beta$-cholan-3,4,24-trioic Acid, a Novel Secondary Bile Acid: Isolation from the Bile of the Common Ringtail Possum (Pseudocheirus peregrinus) and Chemical Synthesis. J Pharmacogn Nat Prod 3: 131. doi: 10.4172/2472-0992.1000131

Copyright: (C) 2017 Sekiguchi S, et al. This is an open-access article distributed under the terms of the Creative Commons Attribution License, which permits unrestricted use, distribution, and reproduction in any medium, provided the original author and source are credited. 


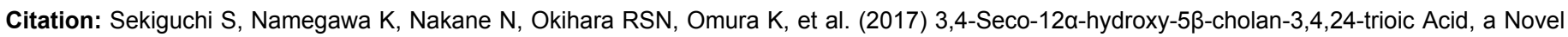
Secondary Bile Acid: Isolation from the Bile of the Common Ringtail Possum (Pseudocheirus peregrinus) and Chemical Synthesis. J Pharmacogn Nat Prod 3: 131. doi: 10.4172/2472-0992.1000131

\section{HPLC-ELSD analysis of gallbladder bile of the common ringtail possum}

The Reversed-Phase High-Performance Liquid Chromatography (RP-HPLC) apparatus used was a JascoLC-2000 plus HPLC system, which consisted of two PU-2085 high-pressure pumps, an MX-2080-32 solvent mixing module, a DG-980-50 degasser, and a CO-2060 column heater with a ChromNAV data processing system (Tokyo, Japan). A Capcell Pack type $\mathrm{C}_{18}$ AQ RP-column $(3.0 \mathrm{~mm} \times 150 \mathrm{~mm}$ I.D.; particle size, $5 \mu \mathrm{m}$; Shiseido, Tokyo, Japan) was employed and kept at $37^{\circ} \mathrm{C}$. An Alltech 2000ES Evaporative Light-Scattering Detector (ELSD; Deerfield, IL, USA) was used under the following conditions: The flow rate of purified compressed air used as a nebulizing gas was $2.2 \mathrm{~L} / \mathrm{min}$ and the temperature of the heated drift was $80.9^{\circ} \mathrm{C}$. The mobile phase used was a mixture of $15 \mathrm{mM}$-ammonium acetate/acetic acid buffer solution ( $\mathrm{pH} 5.0)$ and methanol $(38: 62, \mathrm{v} / \mathrm{v})$; the flow rate was kept at isocratic conditions of $0.4 \mathrm{~mL} / \mathrm{min}$ during the analysis.

\section{Isolation of major biliary bile acids of common ringtail possum by preparative HPLC}

The isopropanol solution of the common ringtail possum was evaporated under a stream of $\mathrm{N}_{2}$, and the residue was dissolved in water $(1.5 \mathrm{~mL})$. The aqueous solution was centrifuged for $10 \mathrm{~min}$ at 2000 $\mathrm{rpm}$, and the supernatant solution was recovered; the procedure was repeated three times for the residue. The total volume of the combined supernatant solution $(4.5 \mathrm{~mL})$ was adjusted to $15 \mathrm{~mL}$ by diluting with water. The solution was passed through a preconditioned Sep-Pak tC18 cartridge (10 g; Waters, Milford, MA, USA). After the cartridge was washed with successively with water $(50 \mathrm{~mL})$ and then with $15 \mathrm{mM}$ ammonium acetate/acetic acid buffer solution ( $\mathrm{pH}$ 5.0) containing $5,10,15,20,25,30,35,40,45,50 \sim 80$, and $100 \%$ methanol. After evaporation of the solvent from each of the fractions, the residues were dried by lyophilization. The residues were then dissolved in methanol and combined supernatant liquids were filtered with a Mini-Uni Pre membrane filter (pore size, $0.45 \mu \mathrm{m}$; Whatman, NJ, USA).

Individual, major bile acids were isolated by preparative HPLC, which consisted of a Hitachi L-7100 pump, a Refraction Index (RI)-102 detectors, and a type $30 \mathrm{~V}$ column heater. For simultaneous separation of unconjugated and glycine- and taurine-amidated bile acids, RPHPLC separation was carried out by isocratic elution modes on a Capcell Pak type $\mathrm{C}_{18}$ AQ RP-column $(10 \mathrm{~mm} \times 250 \mathrm{~mm}$ I.D.; particle size, $5 \mu \mathrm{m}$ ) using a mixture of $15 \mathrm{mM}$ ammonium acetate/acetic acid buffer ( $\mathrm{pH} 5.0)$ and methanol $(35: 65, \mathrm{v} / \mathrm{v})$ as the mobile phase at a flow rate of $3.0 \mathrm{~mL} / \mathrm{min}$. The $65 \%$ methanol fractions, which contained each of compounds A, B, C, D, and F, were collected by evaporation of the solvent, followed by vacuum freeze-drying. Figure 3 shows the HPLCELSD result that was obtained; the identities of individual peaks $\mathrm{A} \sim \mathrm{H}$ are discussed in the Results section.

\section{HR-LC/ESI-MS analysis of isolated compounds}

High-resolution liquid chromatography-mass spectra with an electrospray ionization (HR-LC/ESI-MS) were carried out using a JEOL Accu TOF LC-plus liquid chromatography-mass spectrometer equipped with an ESI source and coupled to an Agilent 1200 series binary pump (Agilent Technologies Inc., Santa Clara, CA, USA) operated in the negative mode. HR-LC/ESI-MS of isolated compounds were carried out in the following injection mode, using a mixture of $5 \mathrm{mM}$ ammonium acetate/acetic acid buffer solution ( $\mathrm{pH} 4.4)$ and methanol $(33: 67, \mathrm{v} / \mathrm{v})$ on a Capcell Pak type AQ RP-column (150 mm $\times 3.0 \mathrm{~mm}$ I.D; particle size, $3 \mu \mathrm{m}$ ); the flow rate was kept at isocratic conditions of $0.2 \mathrm{~mL} / \mathrm{min}$ during the analysis. The ionization conditions were as follows: needle voltage, $-2.0 \mathrm{kV}$; ion source temperature, $80^{\circ} \mathrm{C}$; desolvating plate temperature, $250^{\circ} \mathrm{C}$; absolute ring-lens voltage, $-15 \mathrm{~V}$; mass range, $\mathrm{m} / \mathrm{z}$ 50-1000; nebulizing gas, nitrogen gas $\left(\mathrm{N}_{2}\right)$.

\section{${ }^{1} \mathrm{H}$ and ${ }^{13} \mathrm{C}$ NMR analysis of isolated compounds}

NMR spectra were recorded at $23^{\circ} \mathrm{C}$ in $\mathrm{CDCl}_{3}$ or pyridine- $\mathrm{d}_{5}$ on a JEOL ECA-500 instrument using $500.2 \mathrm{MHz}$ for ${ }^{1} \mathrm{H}$ and $125.8 \mathrm{MHz}$ for ${ }^{13} \mathrm{C}$. The ${ }^{1} \mathrm{H}$ and ${ }^{13} \mathrm{C}$ resonance assignments were made using a combination of Two-Dimensional (2D) homonuclear $\left({ }^{1} \mathrm{H}-{ }^{1} \mathrm{H}\right)$ and heteronuclear $\left({ }^{1} \mathrm{H}-{ }^{13} \mathrm{C}\right)$ shift-correlated techniques, which include ${ }^{1} \mathrm{H}-{ }^{1} \mathrm{H}$ COSY correlation, ${ }^{1} \mathrm{H}$ Nuclear Overhauser And Exchange Spectroscopy (NOESY), ${ }^{1} \mathrm{H}$ detected heteronuclear multiple quantum coherence (HMQC; ${ }^{1} \mathrm{H}-{ }^{13} \mathrm{C}$ coupling), and ${ }^{1} \mathrm{H}$ detected heteronuclear multiple bond connectivity (HMBC; long-range ${ }^{1} \mathrm{H}-{ }^{13} \mathrm{C}$ coupling) experiments. These 2D-NMR spectra were recorded using standard pulse sequences and parameters recommended by the manufacturer. The ${ }^{13} \mathrm{C}$ distortion less enhancement by polarization transfer (DEPT; $135^{\circ}, 90^{\circ}$, and $45^{\circ}$ ) spectra were also measured to determine the exact ${ }^{13} \mathrm{C}$ signal multiplicity and to differentiate between $\mathrm{CH}_{3}, \mathrm{CH}_{2}, \mathrm{CH}$, and $\mathrm{C}$ based on their proton environments.

\section{Synthesis of reference standards}

Chemical synthesis of $3 \alpha, 7 \beta, 12 \alpha$-trihydroxy-5 $\beta$-cholan-24-oyl taurine: To a magnetically stirred solution of unconjugated $3 \alpha, 7 \beta, 12 \alpha-$ trihydroxy-5 $\beta$-cholan-24-oic acid (10.4 $\mathrm{mg}, 25 \mu \mathrm{mol}$ ) [8] in $\mathrm{N}, \mathrm{N}$ dimethylformamide $(2 \mathrm{~mL})$ was added successively taurine $(80 \mu \mathrm{mol})$, 4-(4,6-dimethoxy-1,3,5-triazin-2-yl)-4-methylmorpholinium chloride $\mathrm{n}$-hydrate (DMT-MM; $40 \mu \mathrm{mol})$ and trimethylamine $(50 \mu \mathrm{L})$. The resulting mixture was stirred overnight at room temperature. The reaction mixture was adjusted to $\mathrm{pH} 12$ with $10 \% \mathrm{NaOH}$ and then to $\mathrm{pH} 8$ with $10 \% \mathrm{HCl}$. The solution was diluted with water $(18 \mathrm{~mL})$ and passed through a preconditioned Sep-Pak tC18 (5 g) cartridge. After the cartridge was washed with water $(50 \mathrm{~mL})$, the desired taurine-conjugated bile acid was eluted with $50 \%$ aqueous methanol. After evaporation of the solvent, the residue was recrystallized from methanol-EtOAc as colorless amorphous solid. M.p., $215-218^{\circ} \mathrm{C}$; yield, $12 \mathrm{mg}(91 \%) .{ }^{1} \mathrm{H}-\mathrm{NMR}$ (pyridine- $\mathrm{d}_{5}$ ) $\delta: 0.71$ $\left(3 \mathrm{H}, \mathrm{s}, 18-\mathrm{CH}_{3}\right), 0.93\left(3 \mathrm{H}, \mathrm{s}, 19-\mathrm{CH}_{3}\right), 1.11\left(3 \mathrm{H}, \mathrm{d}, \mathrm{J}=6.3 \mathrm{~Hz}, 21-\mathrm{CH}_{3}\right), 3.39$ $\left(2 \mathrm{H}, \mathrm{m},-\mathrm{CH}_{2} \mathrm{SO}_{3} \mathrm{H}\right), 3.70-3.85(2 \mathrm{H}, \mathrm{brm}, 3 \beta$ - and $7 \mathrm{\alpha}-\mathrm{H}), 4.12(3 \mathrm{H}, \mathrm{m}, 12 \beta-$ $\mathrm{H}$ and $-\mathrm{NHCH}_{2}-$ ). HR-LC/ESI-MS, calculated for $\mathrm{C}_{26} \mathrm{H}_{44} \mathrm{NO}_{7} \mathrm{~S}, 514.2839$ [M-H]; found, $\mathrm{m} / \mathrm{z} 514.2837$.

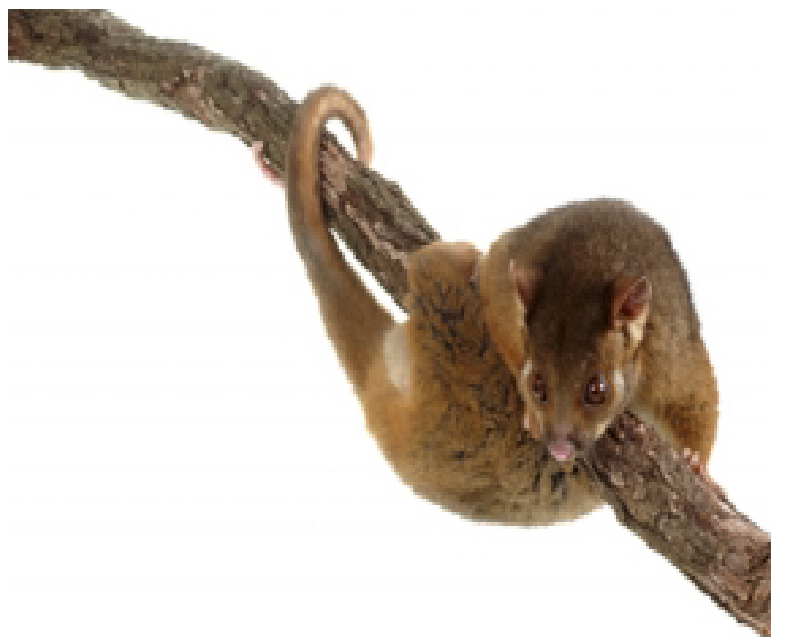

Figure 1: Photograph of the common ringtail possum (Pseudocheirus peregrinus). 


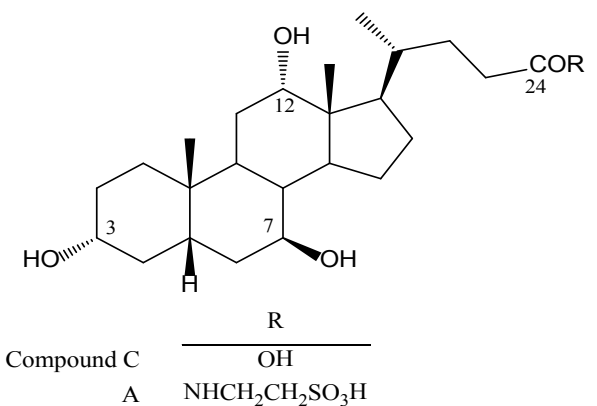

A $\quad \mathrm{NHCH}_{2} \mathrm{CH}_{2} \mathrm{SO}_{3} \mathrm{H}$<smiles>[2H][C@]1(C(=O)O)CCC2C3CC[C@H]([C@H](C)CCC(=O)O)[C@]3(C)[C@@H](O)CC2[C@]1(C)CCC(=O)O</smiles>

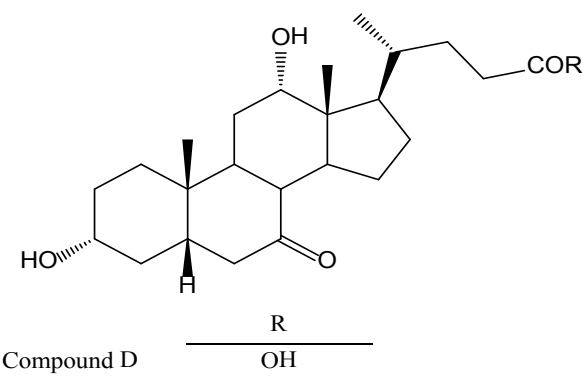

B $\quad \mathrm{NHCH}_{2} \mathrm{CH}_{2} \mathrm{SO}_{3} \mathrm{H}$

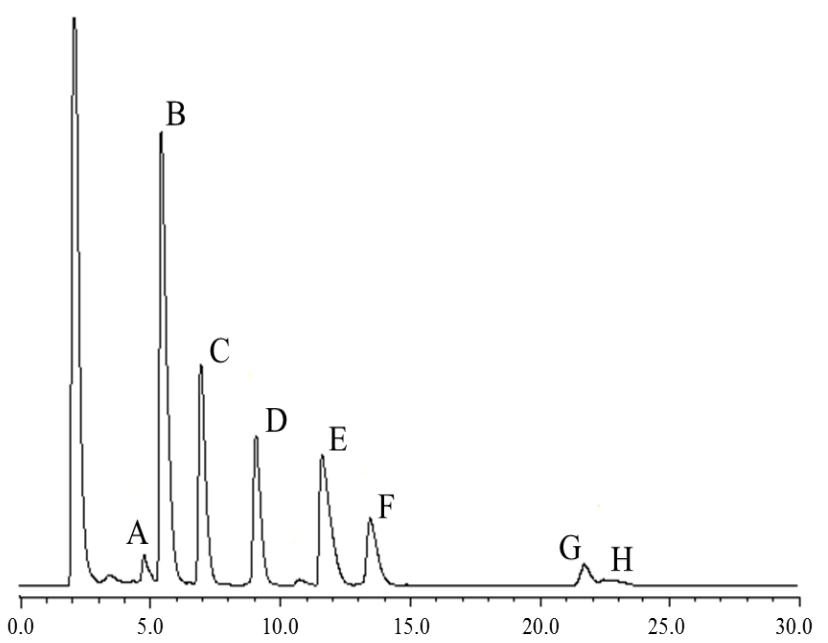

Figure 3: HPLC-ELSD profile of the biliary bile acids of the common ringtail possum.

Chemical synthesis of $3 \alpha, 12 \alpha$-dihydroxy-7-oxo-5 $\beta$-cholan24-oyl taurine: $3 \alpha, 12 \alpha$-Dihydroxy-7-oxo-5 $\beta$-cholan-24-oic acid (10.3 $\mathrm{mg}, 25 \mu \mathrm{mol}$ ) [9] was converted to its taurine conjugate by the method as described for the preparation of $3 \alpha, 7 \beta, 12 \alpha$-trihydroxy- $5 \beta$ cholan-24-oyl taurine: m.p., $212-214^{\circ} \mathrm{C}$ (colorless amorphous solid from methanol-EtOAc); yield, $11 \mathrm{mg}(82 \%) .{ }^{1} \mathrm{H}-\mathrm{NMR}$ (pyridine- $\left.\mathrm{d}_{5}\right) \delta$ : $0.64\left(3 \mathrm{H}, \mathrm{s}, 18-\mathrm{CH}_{3}\right), 1.06\left(3 \mathrm{H}, \mathrm{d}, \mathrm{J}=6.3 \mathrm{~Hz}, 21-\mathrm{CH}_{3}\right), 1.11(3 \mathrm{H}, \mathrm{s}, 19-$ $\left.\mathrm{CH}_{3}\right), 3.42\left(2 \mathrm{H}, \mathrm{m},-\mathrm{CH}_{2} \mathrm{SO}_{3} \mathrm{H}\right), 3.70(1 \mathrm{H}, \mathrm{brm}, 3 \beta-\mathrm{H}), 4.10-4.15(3 \mathrm{H}$, $\mathrm{m}, 12 \beta-\mathrm{H}$ and $-\mathrm{NHCH}_{2}-$ ). HR-LC/ESI-MS, calculated for $\mathrm{C}_{26} \mathrm{H}_{42} \mathrm{NO}_{7} \mathrm{~S}$, $512.2682[\mathrm{M}-\mathrm{H}]-$; found, $\mathrm{m} / \mathrm{z} 512.2678$.

Chemical synthesis of 3,4-seco-12 $\alpha$-acetoxy-5 $\beta$-cholan-3,4,24trioic acid 24-methyl ester (3): The synthetic scheme used to prepare 3,4-seco-12 $\alpha$-hydroxy-5 $\beta$-cholan-3,4,24-trioic acid (1), starting from deoxycholic acid ( $3 \alpha, 12 \alpha$-dihydroxy- $5 \beta$-cholan-24-oic acid; DCA) via methyl $3 \beta, 4 \beta$-dihydroxy- $12 \alpha$-acetoxy- $5 \beta$-cholan-24-oate (2) is shown in Figure 4.

To a magnetically stirred solution of of compound $2(31 \mathrm{mg}, 55$ $\mu \mathrm{mol})$, prepared from DCA in 4 steps [10], in acetone $(2 \mathrm{~mL})$ was added a solution of sodium periodate $\left(\mathrm{NaIO}_{4}, 50 \mathrm{mg}\right)$ dissolved in water $(1.5$ $\mathrm{mL}$ ). After the mixture was stirred at room temperature for $2 \mathrm{~h}$, the reaction product was extracted with EtOAc. The combined extract was washed with water to neutrality, dried with Drierite, and evaporated to an oily residue. To a solution of the residue dissolved in acetone $(2 \mathrm{~mL})$ was added three drops of Jones reagent, and the mixture was stirred at room temperature for $30 \mathrm{~min}$. After adding a few drops of 2-propanol, the reaction product was extracted with $\mathrm{CH}_{2} \mathrm{Cl}_{2}$. The combined organic layer was washed with water, dried with Drierite, and evaporated to give an oily residue. Chromatography of the residue on a column of silica gel (1.0 g) and elution with hexane-EtOAc-acetic acid (150:50:1, $\mathrm{v} / \mathrm{v} / \mathrm{v}$ ) afforded the title compound (3) which recrystallized from EtOAc-hexane as colorless amorphous crystals: m.p., $145-148^{\circ} \mathrm{C}$; yield, $19 \mathrm{mg}(58 \%) .{ }^{1} \mathrm{H}-\mathrm{NMR}$ (pyridine- $\left.\mathrm{d}_{5}\right) \delta: 0.64\left(3 \mathrm{H}, \mathrm{s}, 18-\mathrm{CH}_{3}\right), 0.81(3 \mathrm{H}$, d, J=5.7 Hz, 21- $\left.\mathrm{CH}_{3}\right), 0.94\left(3 \mathrm{H}, \mathrm{s}, 19-\mathrm{CH}_{3}\right), 1.91\left(3 \mathrm{H}, \mathrm{s},-\mathrm{OCOCH}_{3}\right), 3.58$ $\left(3 \mathrm{H}, \mathrm{s},-\mathrm{COOCH}_{3}\right), 5.21(1 \mathrm{H}, \mathrm{m}, 12 \beta-\mathrm{H})$. HR-LC/ESI-MS, calculated for $\mathrm{C}_{27} \mathrm{H}_{41} \mathrm{O}_{8}, 493.2801[\mathrm{M}-\mathrm{H}]$; found, $\mathrm{m} / \mathrm{z}$ 493.2796.

Chemical synthesis of 3,4-seco-12 $\alpha$-hydroxy-5 $\beta$-cholan-3,4,24trioic acid (1): A solution of compound $3(19 \mathrm{mg}, 31 \mu \mathrm{mol})$ in $10 \%$ methanolic $\mathrm{KOH}(2 \mathrm{~mL})$ was refluxed for $1 \mathrm{~h}$. Most of the solvent was evaporated under reduced pressure, and the residue was dissolved in water and then acidified with $10 \% \mathrm{H}_{2} \mathrm{SO}_{4}$ with ice-bath cooling. The precipitated solid was filtered, washed with water, and dried. The crude product was recrystallized from methanol as colorless amorphous crystals. M.p., $217-220^{\circ} \mathrm{C}$; yield, $11 \mathrm{mg}(65 \%) .{ }^{1} \mathrm{H}-\mathrm{NMR}$ (pyridine- $\mathrm{d}_{5}$ ) $\delta: 0.71\left(3 \mathrm{H}, \mathrm{s}, 18-\mathrm{CH}_{3}\right), 0.99\left(3 \mathrm{H}, \mathrm{s}, 19-\mathrm{CH}_{3}\right), 1.17(3 \mathrm{H}, \mathrm{d}, \mathrm{J}=6.3 \mathrm{~Hz}, 21-$ $\left.\mathrm{CH}_{3}\right), 4.16(1 \mathrm{H}, \mathrm{m}, 12 \beta-\mathrm{H})$. HR-LC/ESI-MS, calculated for $\mathrm{C}_{24} \mathrm{H}_{37} \mathrm{O}_{7}$, $437.2539[\mathrm{M}-\mathrm{H}]$; found, $\mathrm{m} / \mathrm{z} 437.2532$. 

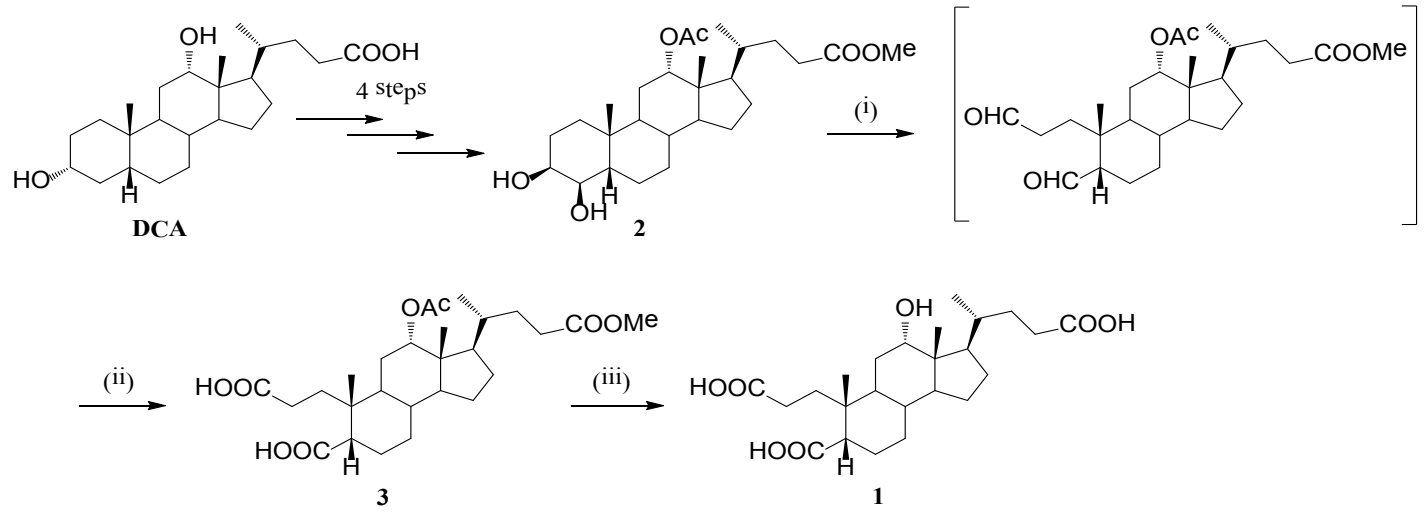

Reagents and conditions: (i) $\mathrm{NaIO}_{4} / \mathrm{H}_{2} \mathrm{O} /$ acetone, r.t. for 2 h. (ii) Jones reagent/acetone, r.t. for $30 \mathrm{~min}$. (iii) $\mathrm{NaOH} / \mathrm{MeOH}$, reflux for 1 h.

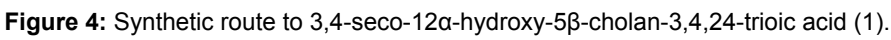

\section{Results}

\section{Biliary bile acid composition}

Figure 3 shows a representative HPLC-ELSD chromatogram of the bile acid composition in the gallbladder bile of the common ringtail possum. Table 1 gives the RRTs of each peak $(\mathrm{A} \sim \mathrm{H})$ observed using HPLC-ELSD as well as their HR-LC/ESI-MS data. Identification of the major peaks was made by a direct comparison with authentic reference compounds prepared in our laboratory. Thus, peak E (16.5\% of total bile acids) was found to be cholyl taurine $(3 \alpha, 7 \alpha, 12 \alpha$-trihydroxy- $5 \beta$ cholan-24-oyl taurine); peak G (2.4\%) was unconjugated cholic acid (3a,7 $\alpha, 12 \alpha$-trihydroxy-5 $\beta$-cholan-24-oic acid; CA); and peak $\mathrm{H}(1.3 \%)$

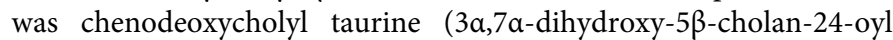
taurine).

The remaining compounds $\mathrm{A} \sim \mathrm{D}$ and $\mathrm{F}$ were each isolated as a single peak by preparative HPLC-RI, and their HR-LC/ESIMS $\mathrm{m} / \mathrm{z}$ values were measured. Peaks A (m/z 514.2844) gave the deprotonated molecular ion [M-H] of $\mathrm{C}_{26} \mathrm{H}_{44} \mathrm{NO}_{7} \mathrm{~S}$ corresponding to a $\mathrm{C}_{24}$ trihydroxy-taurine-conjugated bile acid. Peak C (m/z 407.2828) $\mathrm{C}_{24} \mathrm{H}_{39} \mathrm{O}_{5}$, corresponded to a $\mathrm{C}_{24}$ trihydroxy acid (unconjugated). Peak $\mathrm{B}\left(\mathrm{m} / \mathrm{z}\right.$ 512.2656; $\left.\mathrm{C}_{26} \mathrm{H}_{42} \mathrm{NO}_{7} \mathrm{~S}\right)$ corresponded to a $\mathrm{C}_{24}$ dihydroxymonooxo taurine conjugate, whereas peak $\mathrm{D}\left(\mathrm{m} / \mathrm{z} 405.2625 ; \mathrm{C}_{24} \mathrm{H}_{37} \mathrm{O}_{5}\right)$ was likely to be $\mathrm{a}_{24}$ dihydroxy-monooxo acid. The isolated compound C (18.2\%) was identified as $3 \alpha, 7 \beta, 12 \alpha$-trihydroxy- $5 \beta$-cholan-24-oic acid (ursocholic acid; 7-epicholic acid) [8], whereas D (12.7\%) was found to be $3 \alpha, 12 \alpha$-dihydroxy-7-oxo- $5 \beta$-cholan-24-oic acid (7-oxodeoxycholic acid, 7-oxo-DCA; 7-dehydrocholic acid) [9]. The retention times by HPLC-ESLD and the NMR spectra of these compounds were identical to those of authentic reference compounds as shown in Figure 2. Taurine conjugation of the compounds $\mathrm{C}$ and $\mathrm{D}$ yielded the corresponding $3 \alpha, 7 \beta, 12 \alpha$-trihydroxy- $5 \beta$-cholan-24-oyl taurine (compound $\mathrm{A} ; 2.1 \%$ ) and $3 \alpha, 12 \alpha$-dihydroxy-7-oxo-5 $\beta$-cholan-24-oyl taurine (compound $\mathrm{B} ; 38.9 \%$ ), respectively. To detail, $\mathrm{N}$-acylamidation of the C-24 carboxyl group in synthetic ursocholic acid (compound C) [8] and 7-oxo-DCA (compound D) [9] was effectively attained using taurine $(80 \mu \mathrm{mol})$ as a condensing reagent and DMT-MM (40 $\mu \mathrm{mol})$ and trimethylamine $(50 \mu \mathrm{L})$ as catalysts. After the condensation reaction, the resulting solutions were adjusted to appropriate $\mathrm{pH}$ by acid addition, and the desired taurine conjugates were recovered by applying a reverse-phase pre-packed cartridge, Sep-Pak $\mathrm{tC}_{18}$, for solidphase extraction.
The structure of the unknown compound $\mathrm{F}(7.9 \%)$ was then subjected to further analysis. By HR-LC/ESI-MS analysis, peak F showed $\mathrm{m} / \mathrm{z} 437.2539$, indicating the deprotonated molecule ion [M$\mathrm{H}]^{-}$of $\mathrm{C}_{24} \mathrm{H}_{37} \mathrm{O}_{7}$. This observation strongly suggested that the unknown $\mathrm{F}$ was a novel bile acid having three carboxyl groups, i.e., a seco bile acid. Table 2 shows the ${ }^{1} \mathrm{H}$ and ${ }^{13} \mathrm{C}$ NMR spectral data for naturally occurring compound $\mathrm{F}$ as well as that of synthetic 3,4-seco-12 $\alpha$-dihydroxy-5 $\beta$ cholan-3,4,24-trioic acid (1). The ${ }^{1} \mathrm{H}$ and ${ }^{13} \mathrm{C}$ NMR spectral patterns of both the compounds were essentially identical. Thus, the 18-, 19and 21- $\mathrm{CH}_{3}$ signals in the both ${ }^{1} \mathrm{H}$ NMR spectra were observed at 0.71 (singlet; s), 0.99 (s) and 1.17 (doublet) ppm, along with the $12 \beta-\mathrm{H}$ at $4.16 \mathrm{ppm}$ (multiplet). Furthermore, these compounds showed three characteristic signals arising from carboxyl groups at 176.4, 176.5 and $177.2 \mathrm{ppm}$ and at $72.3 \mathrm{ppm}$ due to the $12 \beta-\mathrm{H}$ bearing a $12 \alpha$-hydroxyl group in the ${ }^{13} \mathrm{C}$ NMR spectra.

In order to determine the position of the three carboxyl groups in compound F, the HMBC spectrum was measured as shown in Figure 5. The three peaks occurred at $176.4,176.5$, and $177.2 \mathrm{ppm}$ were correlated with the $2 \alpha-/ 2 \beta-\mathrm{H}_{2}, 23-\mathrm{H}$, and $5 \beta-\mathrm{H}$, respectively, thus suggesting that the carboxyl groups are probably situated at the C-3, C-4, and C-24 positions. The validity of such assignments was further confirmed by measuring the ${ }^{1} \mathrm{H}-{ }^{1} \mathrm{H}$ COSY spectrum of compound $\mathrm{F}$ (Figure 6). The correlation peaks were only observed between the $2 \alpha-/ 2 \beta-\mathrm{H}_{2}$ and $1 \alpha-/ 1 \beta-\mathrm{H}_{2}$. Similar couplings were also observed between the $5 \beta-\mathrm{H}$ and $6 \alpha-/ 6 \beta-\mathrm{H}_{2}$. However, no correlation peak was observed between the $3 \beta-\mathrm{H}$ and $2 \alpha-/ 2 \beta-\mathrm{H}_{2}$ or the $5 \beta-\mathrm{H}$ and $4 \alpha-/ 4 \beta-\mathrm{H}_{2}$.

\section{Discussion}

\section{Chemical aspects}

Chemical synthesis of an authentic sample of 3,4-seco-12ahydroxy- $5 \beta$-cholan-3,4,24-trioic acid (1) was attained in 2 steps starting from methyl $3 \beta, 4 \beta$-dihydroxy- $12 \alpha$-acetoxy- $5 \beta$-cholanoate (2), which was obtained in 4 steps from deoxycholic acid (DCA) (Figure 4) [10]. Oxidative cleavage of compound 2 with sodium periodate $[11,12]$ and subsequent treatment of the resulting product with Jones reagent resulted in simultaneous dicarboxylation at C-3 and C-4 to give 3,4-seco-12 $\alpha$-acetoxy-5 $\beta$-cholan-3,4,24-trioic acid 24 -methyl ester (3). Alkaline hydrolysis of the 3 followed by acidification afforded the desired 3,4,24-trioic acid (1). The RRT on the HPLC as well as the ${ }^{1} \mathrm{H}$ and ${ }^{13} \mathrm{C}$ NMR signal patterns of the synthetic trioic acid (1) were in good agreement with those of compound $\mathrm{F}$ isolated from a mixture of the biliary bile acids of the common ringtail possum. 
Citation: Sekiguchi S, Namegawa K, Nakane N, Okihara RSN, Omura K, et al. (2017) 3,4-Seco-12a-hydroxy-5 $\beta$-cholan-3,4,24-trioic Acid, a Novel Secondary Bile Acid: Isolation from the Bile of the Common Ringtail Possum (Pseudocheirus peregrinus) and Chemical Synthesis. J Pharmacogn Nat Prod 3: 131. doi: 10.4172/2472-0992.1000131

Page 5 of 8

\begin{tabular}{|c|c|c|c|c|c|c|}
\hline Peak & $\begin{array}{l}\text { Retention } \\
\text { time }^{\text {a }}(\mathrm{min})\end{array}$ & $\begin{array}{c}\text { Percentage } \\
\text { composition (\%) }\end{array}$ & $\begin{array}{l}\text { Observed } \\
\text { HR-LC/ESI-MS } \\
{[\mathrm{M}-\mathrm{H}]^{-} \text {data }}\end{array}$ & $\begin{array}{l}\text { Calculated } \\
\text { mass data }\end{array}$ & & Estimated structure \\
\hline A & 4.8 & 2.1 & 514.2844 & 514.2839 & $\mathrm{C}_{26} \mathrm{H}_{44} \mathrm{NO}_{7} \mathrm{~S}$ & $\mathrm{C}_{24}$ trihydroxy taurine conjugate \\
\hline B & 5.5 & 38.9 & 512.2656 & 512.2682 & $\mathrm{C}_{26} \mathrm{H}_{42} \mathrm{NO}_{7} \mathrm{~S}$ & $\mathrm{C}_{24}$ dihydroxy-monooxo taurine conjugate \\
\hline C & 7.0 & 18.2 & 407.2828 & 407.2798 & $\mathrm{C}_{24} \mathrm{H}_{39} \mathrm{O}_{5}$ & $\mathrm{C}_{24}$ trihydroxy acid \\
\hline $\mathrm{D}$ & 9.2 & 12.7 & 405.2625 & 405.2641 & $\mathrm{C}_{24} \mathrm{H}_{37} \mathrm{O}_{5}$ & $\mathrm{C}_{24}$ dihydroxy-monooxo acid \\
\hline E & 11.7 & 16.5 & 514.2828 & 514.2839 & $\mathrm{C}_{26} \mathrm{H}_{44} \mathrm{NO}_{7} \mathrm{~S}$ & $\mathrm{C}_{24}$ trihydroxy taurine conjugate \\
\hline $\mathrm{F}$ & 13.6 & 7.9 & 437.2539 & 437.2539 & $\mathrm{C}_{24} \mathrm{H}_{37} \mathrm{O}_{7}$ & $\mathrm{C}_{24}$ seco-monohydroxy trioic acid \\
\hline G & 21.8 & 2.4 & 407.2803 & 407.2798 & $\mathrm{C}_{24} \mathrm{H}_{39} \mathrm{O}_{5}$ & $\mathrm{C}_{24}$ trihydroxy acid \\
\hline $\mathrm{H}$ & 22.5 & 1.3 & 498.2898 & 498.2889 & $\mathrm{C}_{26} \mathrm{H}_{44} \mathrm{NO}_{6} \mathrm{~S}$ & $\mathrm{C}_{24}$ dihydroxy taurine conjugate \\
\hline
\end{tabular}

aMeasured on a capcell pak type $\mathrm{C}_{18} \mathrm{AQ}$ reversed-phase column, eluting with a mixture of $15 \mathrm{mM}$-ammonium acetate/acetic acid buffer ( $\left.\mathrm{pH} 5.0\right)$ and methanol (38:62, v/v).

Table 1: HPLC and HR-ESI-MS data of the bile salts present in the biliary bile of the common ringtail possum.

\begin{tabular}{|c|c|c|c|c|c|c|c|c|c|c|c|c|}
\hline \multirow[t]{2}{*}{$\begin{array}{c}\text { Carbon } \\
\text { No. }\end{array}$} & \multicolumn{2}{|c|}{ Compound A } & \multicolumn{2}{|c|}{ Compound C } & \multicolumn{2}{|c|}{ Compound B } & \multicolumn{2}{|c|}{ Compound D } & \multicolumn{2}{|c|}{ Compound F } & \multicolumn{2}{|c|}{$\begin{array}{l}\text { Synthetic } 3,4 \text {-seco-12 } \alpha- \\
\text { hydroxy-5 } \beta \text {-cholan- } \\
\text { 3,4,24-trioic acid (1) }\end{array}$} \\
\hline & ${ }^{13} \mathrm{C}$ & ${ }^{1} \mathrm{H}$ & ${ }^{13} \mathrm{C}$ & ${ }^{1} \mathbf{H}$ & ${ }^{13} \mathrm{C}$ & ${ }^{1} \mathrm{H}$ & ${ }^{13} \mathrm{C}$ & ${ }^{1} \mathrm{H}$ & ${ }^{13} \mathrm{C}$ & ${ }^{1} \mathrm{H}$ & ${ }^{13} \mathrm{C}$ & ${ }^{1} \mathrm{H}$ \\
\hline 1 & 35.56 & - & 35.60 & - & 34.56 & - & 34.57 & - & 35.13 & - & 35.12 & - \\
\hline 2 & 31.23 & - & 31.24 & - & 30.67 & - & 30.69 & - & 29.70 & - & 29.68 & - \\
\hline 3 & 70.94 & 3.76 (brm) & 70.96 & 3.76 (brm) & 70.23 & 3.72 (brm) & 70.22 & 3.72 (brm) & 176.41 & - & 176.42 & - \\
\hline 4 & 38.29 & - & 38.33 & - & 38.39 & - & 38.43 & - & 177.18 & - & 177.17 & - \\
\hline 5 & 43.21 & - & 43.25 & - & 46.81 & - & 46.32 & - & 48.63 & - & 48.59 & - \\
\hline 6 & 38.80 & - & 38.78 & - & 45.69 & - & 45.70 & - & 25.19 & - & 25.19 & - \\
\hline 7 & 70.62 & 3.81 (brm) & 70.63 & 3.81 (brm) & 211.43 & - & 211.37 & - & 26.90 & - & 26.90 & - \\
\hline 8 & 44.42 & - & 44.47 & - & 49.77 & - & 49.78 & - & 36.09 & - & 36.08 & - \\
\hline 9 & 32.53 & - & 32.57 & - & 36.39 & - & 36.42 & - & 39.63 & - & 39.63 & - \\
\hline 10 & 33.99 & - & 34.01 & - & 34.88 & - & 34.89 & - & 36.61 & - & 36.59 & - \\
\hline 11 & 29.99 & - & 30.04 & - & 30.20 & - & 30.27 & - & 30.27 & - & 30.27 & - \\
\hline 12 & 71.76 & $4.12(\mathrm{~m})$ & 71.81 & $4.17(\mathrm{~m})$ & 71.11 & $4.10(\mathrm{~m})$ & 71.13 & $4.12(\mathrm{~m})$ & 72.33 & $4.16(\mathrm{~m})$ & 72.31 & $4.15(\mathrm{~m})$ \\
\hline 13 & 47.69 & - & 47.77 & - & 46.81 & - & 46.88 & - & 46.73 & - & 46.72 & - \\
\hline 14 & 48.32 & - & 48.38 & - & 41.14 & - & 41.22 & - & 47.97 & - & 47.97 & - \\
\hline 15 & 27.20 & - & 27.21 & - & 24.74 & - & 24.80 & - & 24.06 & - & 24.06 & - \\
\hline 16 & 28.40 & - & 28.42 & - & 27.95 & - & 28.04 & - & 27.79 & - & 27.80 & - \\
\hline 17 & 45.87 & - & 46.16 & - & 46.13 & - & 46.37 & - & 47.11 & - & 47.10 & - \\
\hline 18 & 13.06 & $0.71(\mathrm{~s})$ & 13.10 & $0.77(\mathrm{~s})$ & 12.93 & $0.62(\mathrm{~s})$ & 12.96 & 0.69 (s) & 12.85 & $0.71(\mathrm{~s})$ & 12.86 & $0.71(\mathrm{~s})$ \\
\hline 19 & 23.49 & 0.93 (s) & 23.48 & $0.95(\mathrm{~s})$ & 22.92 & $1.10(\mathrm{~s})$ & 22.94 & $1.12(\mathrm{~s})$ & 18.94 & 0.99 (s) & 18.93 & 0.99 (s) \\
\hline 20 & 35.94 & - & 35.86 & - & 35.64 & - & 35.67 & - & 35.80 & - & 35.80 & - \\
\hline 21 & 17.47 & $1.07(\mathrm{~d}, \mathrm{~J} 6.3)$ & 17.48 & $1.18(\mathrm{~d}, \mathrm{~J}$ 5.8) & 17.49 & $1.04(\mathrm{~d}, \mathrm{~J} 6.3)$ & 17.43 & $1.13(\mathrm{~d}, J 5.7)$ & 17.33 & $1.17(\mathrm{~d}, \mathrm{~J} 5.7)$ & 17.33 & $1.17(\mathrm{~d}, J$ J.3) \\
\hline 22 & 32.32 & - & 31.91 & - & 32.17 & - & 31.74 & - & 31.84 & - & 31.82 & - \\
\hline 23 & 33.73 & - & 31.99 & - & 33.55 & - & 31.83 & - & 31.77 & - & 31.76 & - \\
\hline 24 & 174.80 & - & 176.51 & - & 173.71 & - & 176.46 & - & 176.54 & - & 176.54 & - \\
\hline $\mathrm{NCH}_{2}$ & 36.19 & $4.12(\mathrm{~m})$ & - & - & 36.47 & $4.16(\mathrm{~m})$ & - & - & - & - & - & - \\
\hline $\mathrm{CH}_{2} \mathrm{~S}$ & 51.58 & $3.43(\mathrm{~m})$ & - & - & 51.52 & $3.43(\mathrm{~m})$ & - & - & - & - & - & - \\
\hline
\end{tabular}

s: Singlet; d: Doublet; m: Multiplet; brm: Broad Multiplet. ${ }^{2}$ Chemical shifts were expressed as $\delta$ ppm relative to TMS. Values in parentheses refer to coupling constants $(\mathrm{J}$ in $\mathrm{Hz}$ ). Measured in pyridine- $\mathrm{d}_{5}$ at $500.2 \mathrm{MHz}$ in ${ }^{1} \mathrm{H} \mathrm{NMR}$ and at $125.8 \mathrm{MHz}$ in ${ }^{13} \mathrm{C} \mathrm{NMR}$.

Table 2: ${ }^{1} \mathrm{H}$ and ${ }^{13} \mathrm{C}$ NMR signal assignments of isolated and synthetic compounds ${ }^{\mathrm{a}}$.

\section{Biological aspects}

The common ringtail possum (Pseudocheirus peregrinus) is an Australian marsupial (Figure 1). It lives in a variety of habitats (forests, dense scrub and suburban gardens) and eats a variety of leaves of both native and introduced plants, as well as flowers and fruits. The possum is coprophagic, producing two types of feces, one of which is eaten (see below). This behavioral characteristic is also observed in rabbits [13] and both genera have biliary bile acids that are predominantly secondary.

Our study shows that biliary bile acids in the common ringtail possum differ from those of most mammals in at least two ways (Table 3). First, a seco-bile acid was present. As all primary bile acids have a hydroxyl- or oxo-substituent at C-7, it is likely that the seco-bile acid is a secondary bile acid, formed by bacterial enzymes from Deoxycholic Acid (DCA) in the intestine. Second, the majority of bile acids (80\%) appear to be secondary bile acids that have been generated from primary bile acids by bacterial enzymes.

The intermediates in the formation of the seco-bile acid are unknown. The four rings of the bile acid structural platform are generally considered to be stable in vertebrates. However, environmental bacteria have at least two pathways for opening the B ring [14]. We can speculate that the opening of the A ring occurs by an enzymatic pathway that parallels the Baeyer-Villiger oxidation reaction. In this reaction a bile acid with a 3-oxo functional group in the A ring is converted to a pair of regioisomers -3-oxa-4-one-4a-homo- and 3-one-4-oxa-4a-homo. Each of these regioisomers could serve as a precursor for the synthesis of the 3,4-seco bile acid. Other instances where the A ring has been 
Citation: Sekiguchi S, Namegawa K, Nakane N, Okihara RSN, Omura K, et al. (2017) 3,4-Seco-12a-hydroxy-5 $\beta$-cholan-3,4,24-trioic Acid, a Novel Secondary Bile Acid: Isolation from the Bile of the Common Ringtail Possum (Pseudocheirus peregrinus) and Chemical Synthesis. J Pharmacogn Nat Prod 3: 131. doi: 10.4172/2472-0992.1000131

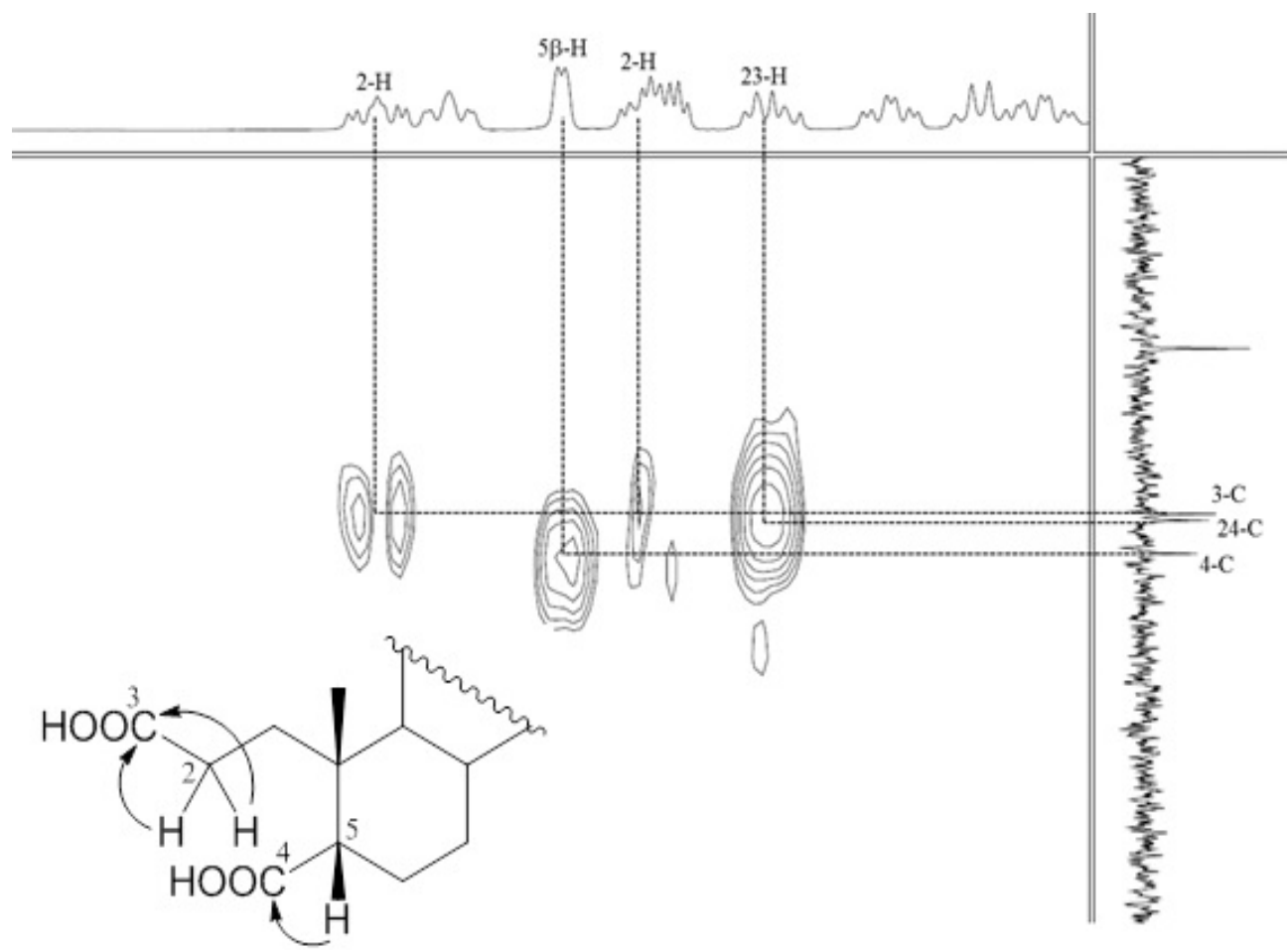

Figure 5: HMBC NMR spectrum of compound F.

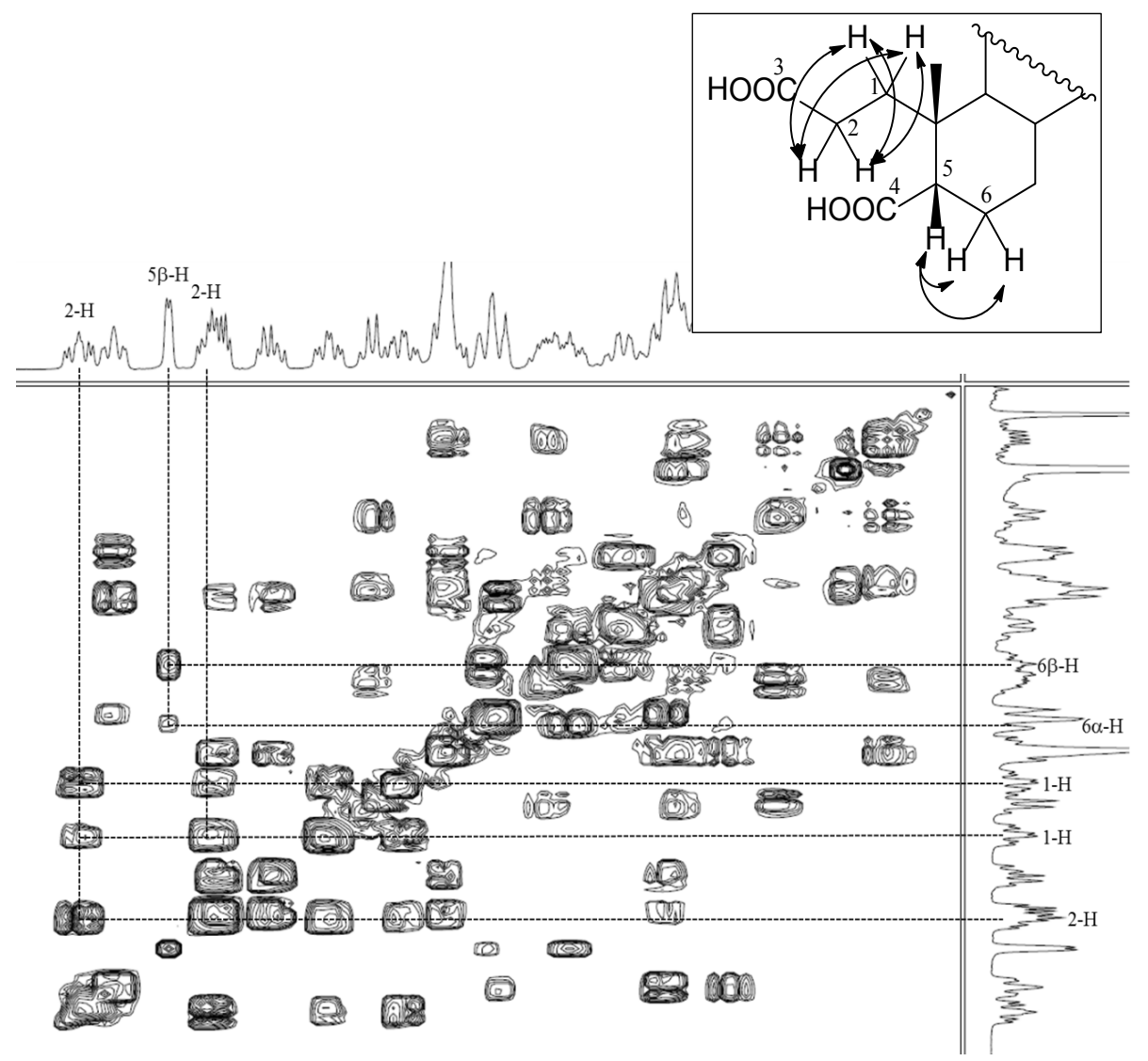

Figure 6: ${ }^{1} \mathrm{H}-{ }^{1} \mathrm{H}$ COSY NMR spectrum of compound $\mathrm{F}$. 
Citation: Sekiguchi S, Namegawa K, Nakane N, Okihara RSN, Omura K, et al. (2017) 3,4-Seco-12a-hydroxy-5 $\beta$-cholan-3,4,24-trioic Acid, a Novel Secondary Bile Acid: Isolation from the Bile of the Common Ringtail Possum (Pseudocheirus peregrinus) and Chemical Synthesis. $J$ Pharmacogn Nat Prod 3: 131. doi: 10.4172/2472-0992.1000131

\begin{tabular}{|c|c|c|}
\hline Bile acid & Peak & $\%$ \\
\hline Unconjugate & $3 \alpha-\mathrm{OH}, 7 \alpha-\mathrm{OH}, 12 \alpha-\mathrm{OH}$ \\
\hline Taurine conjugate & $\mathrm{G}$ & 2.4 \\
\hline & $3 \alpha-\mathrm{OH}, 7 \alpha-\mathrm{OH}$ & 16.5 \\
\hline Taurine conjugate & $\mathrm{H}$ & 1.3 \\
\hline & $3 \alpha-\mathrm{OH}, 7 \beta-\mathrm{OH}, 12 \alpha-\mathrm{OH}$ \\
\hline Unconjugate & $\mathrm{C}$ \\
\hline Taurine conjugate & $\mathrm{A}$ & 18.2 \\
\hline & $3 \alpha-\mathrm{OH}, 7=\mathrm{O}, 12 \alpha-\mathrm{OH}$ \\
\hline Unconjugate & $\mathrm{D}$ & 2.1 \\
\hline Taurine conjugate & $\mathrm{B}$ & 12.7 \\
\hline & $3,4-\mathrm{seco}, 12 \alpha-\mathrm{OH}$ & 38.9 \\
\hline Unconjugate & $\mathrm{F}$ & 7.9 \\
\hline
\end{tabular}

Taurine conjugated bile acids constituted $58.8 \%$ of bile acids.

Table 3: Biliary bile acids of the common ringtail possum ${ }^{a}$

opened are found in 3,4-secoterpenoids [15] and in steroids degraded by the thermophilic fungus Myceliophthora thermophila [16] as well as in steroids mediated by Steroidobacter denitrificans [17].

We propose the following sequence of events to explain the biliary bile acid composition of the possum. The dominant primary acid synthesized is cholic acid which is conjugated with taurine in the liver. In the intestine, cholyltaurine undergoes bacterial deconjugation. The liberated cholic acid is absorbed in part but a fraction in the intestine undergoes oxidation at C-7 by bacterial dehydrogenases to form 7-oxodeoxycholic acid (7-oxo-DCA; 3a,12a-dihydroxy-7-oxo-5 $\beta$-cholan24-oic acid), a fraction of which is absorbed. In the hepatocyte, the 7-oxo-DCA undergoes partial reduction to form cholic acid [18]. In addition, in the intestine, some of the 7-oxo compound is reduced by bacterial enzymes to form ursocholic acid $(3 \alpha, 7 \beta, 12 \alpha$-trihydroxy- $5 \beta$ cholan-24-oic acid), which in turn is absorbed. As a hydrophilic bile acid, it may well be incompletely unconjugated during passage through the hepatocyte [19]. We cannot exclude the possibility that 7-oxo-DCA may also be a primary bile acid.

Ursocholic acid has been reported to be a major bile acid (10\%) in a patient with cholesterol gallstones [20] as well as in a mouse model of cystic fibrosis where it constituted $25 \%$ of biliary bile acids [21]. In both instances, ursocholic acid was considered to be a secondary bile acid. Ursocholic acid has also been reported to be present in the urine [22] and feces [23] of healthy subjects.

The possum is known to engage in coprophagy [24,25]. Feces consist of two types of pellets, the one containing undigested residue, and the other, a "soft" pellet contains cecal content that is likely to include bile acids. The possum ingests the soft pellets, and as a result, colonic content including bile acids is exposed to the vast absorptive surface and the microbiome of the small intestine. Bile acid metabolism in the possum appears to be similar to that of the rabbit whose bile contains predominantly DCA [13].

Our paper confirms previous work attesting the diversity of bile acid structures to be found in Australian marsupials. The 1a-hydroxy derivative (1a-OH-CDCA) of Chenodeoxycholic Acid (CDCA) was shown to be the major bile acid in the Australian opossum Trichosurus vulpecula (Lesson), and dubbed vulpecholic acid [26,27]. This bile acid was also identified in the biliary bile acids of the spotted cuscus (Phalanger maculatus), and $1 \beta$-hydroxy-CDCA was identified in the biliary bile acids of the feather-tailed glider (Acrobates pygmaeus) [6].

Hydroxy-oxo bile acids have also been identified in the biliary bile acids of Australian marsupials, just as observed by us in the biliary bile

acids of the possum. In the Queensland kaola (Pascolarctos adjustus), the kowari (Dasyuroides byrnei) and the spotted-tailed quoll (Dasyrus maculatus), 7-oxo-lithocholic acid (3a-hydroxy-7-oxo-5 $\beta$-cholan-24oic acid) is a dominant biliary bile acid [6].

\section{Phylogenetic aspects}

It is generally believed that the marsupials (Metatheria) are an old and relatively less advanced lineage that spilt away from their sister group of placental mammals (Eutheria) at some point deep in geologic time. The structures of bile salts found in the bile of marsupials do not support this idea. Primitive extant mammals still alive today (Paenungulates) utilize a mixture of $\mathrm{C}_{27}$ bile alcohols. The supposedly older and even more primitive marsupials should also feature a similar suite of bile salts. Instead, what is found is a series of derived $\mathrm{C}_{24}$ bile acids. It is apparent that the switch from bile alcohols to bile acids, and the utilization of taurine for conjugation had already occurred in marsupials far earlier in time than the last common precursor of marsupials and eutherian mammals (estimated to be more than 100 million years ago). Currently, the marsupial lineage is an active site of bile acid evolution, with different species exhibiting new and structurally unique bile salts as noted above $[1,2,5,6]$.

\section{Acknowledgements}

This work was supported in part by a Grant-in-Aid for Scientific Research (C) from the Japan Society of Promotion of Science (to T.I., 15K01809) for 2015-2017. Work at University California, San Diego was also supported in part a grant from the American Physiological Society.

\section{References}

1. Hofmann AF, Hagey LR (2008) Bile acids: chemistry, pathochemistry, biology, pathobiology, and therapeutics. Cell Mol Life Sci 65: 2461-2483.

2. Hofmann AF, Hagey LR (2014) Key discoveries in bile acid chemistry and biology and their clinical applications: history of the last eight decades. J Lipid Res 55: 1553-1595.

3. Zhou H, Hylemon PB (2014) Bile acids are nutrient signaling hormones Steroids 86: 62-68

4. Haslewood GAD (1967) Bile salt evolution. J Lipid Res 8: 535-550.

5. Hofmann AF, Hagey LR, Krasowski MD (2010) Bile salts of vertebrates: structural variation and possible evolutionary significance. J Lipid Res 51: 226-246.

6. Hagey LR, Vidal N, Hofmann AF, Krasowski MD (2010) Evolutionary diversity of bile salts in reptiles and mammals, including analysis of ancient human and extinct giant ground sloth coproplites. BMC Evol Biol 10: 133-155.

7. Satoh R, Saito T, Ogata H, Ohsaki A, lida T, et al. (2014) N-Methyltaurine $\mathrm{N}$-acyl amidated bile acids and deoxycholic acid in the bile of angelfish (Pomacanthidae): a novel bile acid profile in perciform fish. Steroids 80: 15-23.

8. lida T, Chang FC (1982) Potential bile acid metabolites. 7. 3,7,12-Trihydroxy$5 \beta$-cholanic acids and related compounds. J Org Chem 47: 2972-2978.

9. Iida T, Komatsubara I, Yoda S, Goto J, Nambara T, et al. (1990) Potential bile

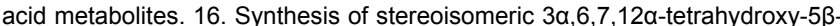
cholanoic acids. Steroids 55: 530-539.

10. lida T, Momose T, Chang FC, Goto J, Nambara T (1989) Potential bile acid metabolites. XV. Synthesis of $4 \beta$-hydroxylated bile acids; unique bile acids in human fetal bile. Chem Pharm Bull 37: 3323-3329.

11. Snider BB, Yang K (1990) Stereo- and enantiospecific syntheses of (-)-reiswigins A and B. Assignment of absolute and relative configuration. J Org Chem 55: 4392-4399.

12. Costa VEU, Pohlmann AR, de Sordi MLT (2004) Evaluation of lipases in the desymmetrization of meso-exo-3,5-dihydroxymethylenetricyclo[5.2.02,6]decane and the synthesis of chiral derivatives. J Braz Chem Soc 15: 22-27.

13. Soave O, Brand CD (1991) Coprophagy in animals: A review. Cornell Vet 81 357-364.

14. Holert J, Yücel O, Suvekbala V, Kulic Z, Möller H, et al. (2014) Evidence of distinct pathways for bacterial degradation of the steroid compound cholate 


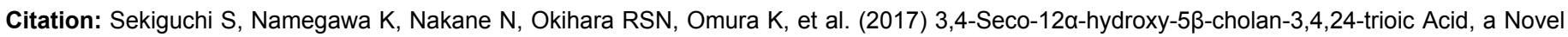
Secondary Bile Acid: Isolation from the Bile of the Common Ringtail Possum (Pseudocheirus peregrinus) and Chemical Synthesis. J Pharmacogn Nat Prod 3: 131. doi: 10.4172/2472-0992.1000131

suggest the potential for metabolic interactions by interspecies cross-feeding. Environ Microbiol 16: 1424-1440.

15. Simoneit BRT, Xu Y, Neto RR, Cloutier JB, Jaffe R (2009) Photochemical alteration of 3-oxygenated triterpenoids: implication for the origin of 3,4-secoterpinoids in sediments. Chemosphere 74: $543-550$.

16. Hunter AC, Watts KR, Dedi C, Dodd HT (2009) An unusual ring-A opening and other reactions in steroid transformation by the thermophilic fungus Myceliophthora thermophila. J Steroid Biochem Mol Biol 116: 171-177.

17. Wang PH, Leu YL, Ismail W, Tang SL, Tsai CY, et al. (2013) Anaerobic and aerobic cleavage of the steroid core ring structure by Steroidobacter denitrificans. J Lipid Res 54: 1493-1504.

18. Nakagaki M, Danzinger RG, Hofmann AF, Roda A (1983) Hepatic biotransformation of two hydroxyl-7-oxotaurine-conjugated bile acids in the dog. Am J Physiol 245: G411-G417.

19. Lillienau J, Hagey LR, Borgström B (1991) Hepatic and ileal transport and effect on biliary secretion of norursocholic acid and its conjugates in rats. Am J Physiol 261: G1057-G1064.

20. Stellaard F, Klein PD, Hofmann AF, Lachin JM (1985) Mass spectrometry identification of biliary bile acids in bile from patients with gallstones before and during treatment with chenodeoxycholic acid. An ancillary study of the National Cooperative Gallstone Study. J Lab Clin Med 105: 504-513.
21. Bodewes FAJA, van der Wulp MYM, Beharry S, Doktorova M, Havinga R, et al. (2015) Altered intestinal bile salt biotransformation in a cystic fibrosis ( $\left.\mathrm{Cftr}^{-/}\right)$ mouse model with hepato-biliary pathology. J Cyst Fibros 14: 440-446.

22. Nakashima T, Sano A, Seto Y, Nakajima T, Nakagawa Y, et al. (1986) Unusua trihydroxy bile acids in the urine of healthy humans. Clin Chim Acta 160: 47-53.

23. Eneroth P, Gordon B, Sjövall J (1966) Characterization of trisubstituted cholanoic acids in human feces. J Lipid Res 7: 524-530.

24. Chilcott MJ, Hume ID (1985) Coprophagy and selective retention of fluid digesta: their role in the nutrition of the common ringtail possum, Pseudocheirus peregrinus. Austral J Zool 33: 1-15.

25. Kenagy GJ, Hoyt DF (1980) Reingestion of feces in rodents and its daily rhythmicity. Oecologia (Berl) 44: 403-409.

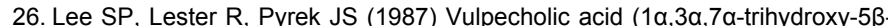
cholan-24-oic acid): a novel bile acid of a marsupial, Trichosurus vulpecula (Lesson). J Lipid Res 28: 19-31.

27. Pyrek JS, Lee SP, Thomsen L, Tasman-Jones C, Leydon B (1991) Bile acids of marsupials. 2. Hepatic formation of vulpecholic acid (1 $\alpha, 3 \alpha, 7 \alpha$-trihydroxy$5 \beta$-cholan-24-oic acid) from chenodeoxycholic acid in a marsupial, Trichosurus vulpecula (Lesson). J Lipid Res 32: 1417-1427. 